\title{
Phylogeny and systematics of Old World serotine bats (genus Eptesicus, Vespertilionidae, Chiroptera): an integrative approach
}

\author{
Javier Juste, Petr Benda, Juan luis Garcia-Mudarra \& Carlos Ibánez
}

\begin{abstract}
Juste, J., Benda, P., Garcia-Mudarra, J.L. \& Ibánez, C.. Phylogeny and systematics of Old World serotine bats (genus Eptesicus, Vespertilionidae, Chiroptera): an integrative approach. -Zoologica Scripta, 00, 000-000.

Integrative taxonomy aims to document biodiversity by incorporating all useful characters to increase confidence in hypotheses about phylogenetic relationships. In this study, we combine data obtained independently from morphology, two maternally inherited mtDNA genes and two biparentally inherited nuDNA genes to make phylogenetic and taxonomic hypotheses about the Palaearctic members of the bat genus Eptesicus (Vespertilionidae). This genus is distributed worldwide (except for Antarctica) and is highly diversified, presenting one of the most entangled taxonomic puzzles among all mammals. Our results support restoring the genus Rhyneptesicus and separating E. isabellinus and E. pachyomus from E. serotinus and E. ognevi and E. anatolicus from E. bottae. Differences in the phylogenetic hypotheses from mtDNA and nuDNA data suggest the occurrence within E. serotinus of evolutionary processes such as mtDNA capture and secondary contacts between partially differentiated ecomorphs. These two evolutionary processes deserve more in-depth studies within the group.

Corresponding author: Javier Juste, Estación Biológica de Donana (CSIC), P.O. Box 1056, 41080 Sevilla, Spain. E-mail: juste@ebd.csic.es

Petr Benda, Department of Zoology, National Museum (Natural History), CZ-115 79 Praha 1, Praha, Czech Republic and Department of Zoology, Charles University, CZ-128 44 Praha 2, Praha, Czech Republic. E-mail: petr_benda@nm.cz

Juan Luis Garcia-Mudarra, and Carlos Ibánez, Estación Biológica de Donana (CSIC), P.O. Box 1056, 41080, Sevilla, Spain. E-mails: juanele@ebd.csic.es; ibanez@ebd.csic.es
\end{abstract}

Introduction

DNA-based approaches provide an extraordinary powerful tool for studying evolutionary relationships among organisms. They are particularly helpful in disentangling relationships and clarifying taxonomy within groups, such as bats in which morphology has been tightly constrained by functional or ecological pressures and therefore may be of limited value in species recognition. In fact, molecular techniques have helped clarify misleading morphological arrangements resulting from convergent evolution (Ruedi \& Mayer 2001) or from morphological conservatism and its related cryptic diversity. Cryptic diversity has been overlooked by traditional taxonomy (Bickford et al. 2007) and appears to be particularly important in many groups of bats such as vespertilionids (e.g. Mayer \& von Helversen 2001; Ibánez et al. 2006; Mayer et al. 2007; Moratelli et al. 2011).

Unfortunately for taxonomists, genes often differ in their evolutionary pathways and as a result they often disagree in their species definition hypotheses (e.g. Edwards 2008; Degnan \& Rosenberg 2009). This disagreement among data sets brings about a big potential for confusion in their derived taxonomic inferences. Among other proposed solutions, the integrative approach (Padial et al. 2010) aims to incorporate all the data types available in an increasing confidence-building process to document biodiversity. The rationale is that congruence among data sets is strong evidence that the underlying historical pattern is being 
recovered, and that the taxonomic conclusions derived from them are robust and stable.

The bat genus Eptesicus Rafinesque, 1820 (Vespertilionidae) poses one of the most entangled taxonomic puzzles among mammals. It consists in an evolutionary successful group of open-flyers bats that lived in a wide variety of environments (from forests to xeric shrubs) and that was once considered distributed in temperate and tropical areas across all continents except Antarctica (Hill \& Smith 1984). Eptesicus was later restricted geographically to the Palaearctic, Africa and the Americas, based on skull and baculum structure and on banded karyotyping (Hill \& Harrison 1987; Volleth \& Tideman 1989; Volleth \& Tidemann 1991; Volleth et al. 2001; Kearney et al. 2002). Recently, molecular studies of the phylogenetic relationships within the family Vespertilionidae have shown that the American Eptesicus are paraphyletic with regard to the Palaearctic forms, and the definition of the genus Eptesicus was extended to include also the American genus Histiotus (Hoofer \& Van Den Bussche 2003; Hoofer et al. 2006; Rohers et al. 2010). Even before this change, the number of recognized species within the genus varied significantly according to the authors and all arranged by Simmons (2005) in three main groups (nasutus, nilssonii and serotinus). The highest diversity within the Palaearctic serotinus is found in the Middle East, where different forms distinguished by coloration, dental and skull features and habitat preferences have been known for over a century. However, their taxonomic relationships have long been disputed. They have been included in or split from the two main species E. serotinus and E. bottae. Moreover, recent molecular approaches have suggested, based only on mitochondrial DNA, species rank for the taxa $E$. isabellinus and $E$. anatolicus (Ibánez et al. 2006; Mayer et al. 2007; Artyushin et al. 2009); this arrangement is also supported by morphological differences (Benda et al. 2004, 2006).

From the analyses of mitochondrial (mtDNA) and nuclear DNA (nuDNA)markers, and using an extensive sampling throughout its vast putative distribution area (from the Atlantic to the Pacific Ocean), we have studied the taxonomy and evolutionary relationships of E. serotinus together with its close $\mathrm{E}$. bottae and examined the validity of most of the taxa described within the subgenus Eptesicus as defined by Hill \& Harrison (1987) and recognized by Simmons (2005), paying special attention to the forms described from and around the Mediterranean Basin. Benda et al. $(2006,2007,2010,2011)$ used morphological characters to revise the taxonomy of most of the specimens examined in this molecular study. This information permits us to evaluate the taxonomic position of all these taxa using an integrative approach, comparing the conclusions obtained independently from morphology, two maternally inherited mtDNA genes and two biparentally inherited nuDNA genes and accepting with confidence only those taxonomic conclusions in which a higher corroboration is obtained by the different approaches (Padial \& De la Riva 2010).

\section{Material and methods}

Sampling

A total of 128 bats from 26 countries in Europe, Africa, America and Asia were included in the study (Appendix 1). The in-group comprises 102 individuals belonging to the genus Eptesicus. The morphological assignment of the vouchers in the studies by Benda et al. (2006, 2007, 2010, 2011) is used as a starting taxonomic consideration in this study. Sampling includes the extremes of the distribution area of E. serotinus, (from England to Laos) as well as several European populations of the species. We include also samples of putative Palaearctic sister species to E. serotinus (Fig. 1) and E. bottae (Fig. 2) from the Middle East to China and Laos, plus E. furinalis, E. diminutus and E. fuscus from America and E. hottentotus from South Africa, all included within the 'serotinus' group (as defined by Hill \& Harrison 1987). Additionally, we included samples from the related species E. nasutus and E. nilssonii. To study the evolutionary relationships of the genus Eptesicus within the family, we included in the analyses of 26 specimens belonging to 14 species representing most of the groups defined within the subfamily Vespertilioninae. A detailed list of the specimens analysed is provided in Appendix 1.

\section{Sequencing}

Genomic DNA was extracted from tissue samples preserved in alcohol by proteinase $\mathrm{K}$ digestion and standard phenol-chloroform protocol (Higuchi et al. 1988; Maniatis et al. 1989). After trying different primer combinations, fragments of the two mtDNA genes, Cytochrome b (Cytb) and NADH dehydrogenase (ND1), were amplified from all samples with the primer pairs MOLCIT-F (Ibánez et al. 2006) and MVZ-16 (Smith \& Patton 1993), and ND1-F2 and ND1-R (Kawai et al. 2002), respectively. The amplifications for both fragments were carried out in a volume of $20 \mathrm{IL}$ containing $0.1 \% \mathrm{BSA}, 2.5 \mathrm{~mm} \mathrm{MgCl}_{2}, 0.5 \mathrm{IL}$ of each primers, $0.2 \mathrm{~mm}$ of each dNTP, 0.5 units of taq-polymerase with appropriate buffer and $\mathrm{H}_{2} \mathrm{O}$. Cytb thermocycling consisted of a four-minute initial denaturation at $94^{\circ} \mathrm{C}$ followed by 35 cycles of $60 \mathrm{~s}$ at $94^{\circ} \mathrm{C}, 30 \mathrm{~s}$ at $45-$ $50{ }^{\circ} \mathrm{C}, 90 \mathrm{~s}$ at $72{ }^{\circ} \mathrm{C}$ and then a final extension of $10 \mathrm{~min}$ at $72{ }^{\circ} \mathrm{C}$. For the ND1 fragment, thermocycling was the same except that the annealing temperature was $60^{\circ} \mathrm{C}$. A fragment of the nuDNA gene recombination-activating gene (RAG2) was amplified using the primers RAG2-F1, RAG2-R2, RAG2-R1 and RAG2-F1int (Baker et al. 2000) 


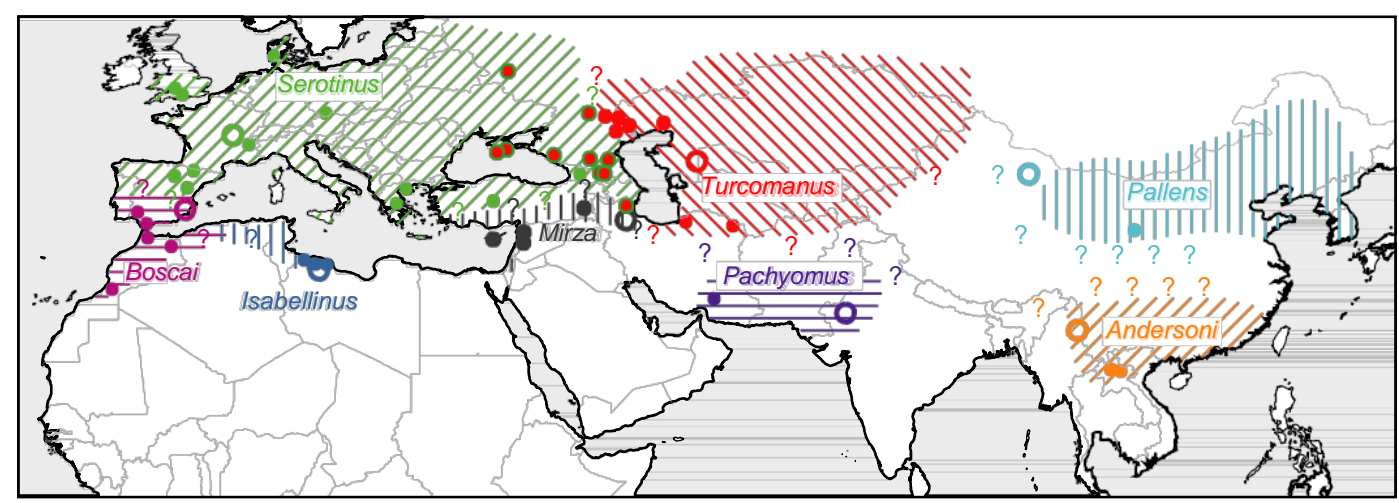

Fig. 1 Approximate distribution map of the taxa included within Eptesicus serotinus according to Simmons (2005) and morphologically identified by Benda et al. $(2006,2007,2010,2011)$ and used in this study plus the recently studied by Artyushin et al. (2009). Open circles indicate the type localities for each taxon and full-coloured circles indicate sampling localities for this paper. Two-coloured cycles indicate individuals with morphological and mitochondrial taxonomic disagreement.

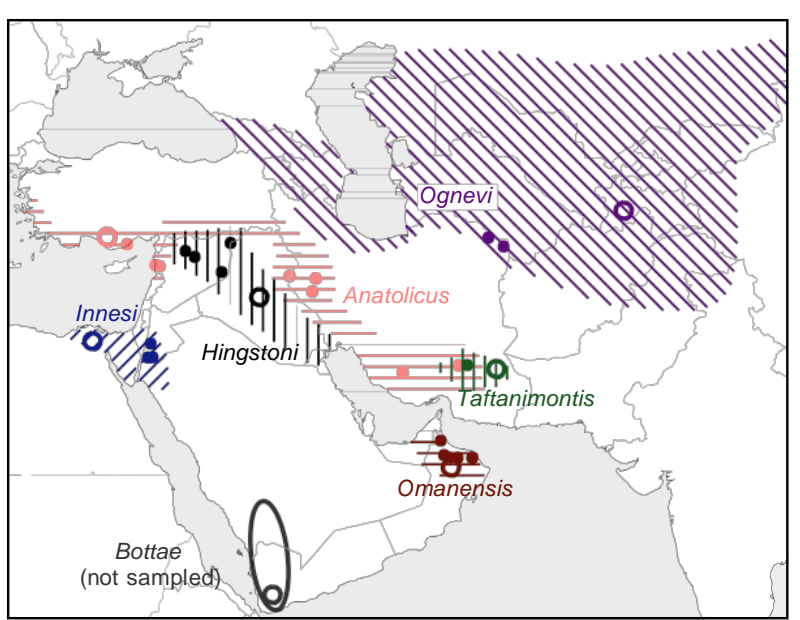

Fig. 2 Approximate distribution map of the taxa included within Eptesicus bottae according to Simmons (2005) and morphologically identified by Benda et al. $(2006,2007,2010,2011)$ and used in this study. Open circles indicate the type localities for each taxon and full-coloured circles indicate sampling localities for this paper.

as internal primers. In this case, the PCRs were conducted with $0.75 \mathrm{IL}$ of each primer and $2 \mathrm{~mm}$ of $\mathrm{MgCl}_{2}$. Thermocycler steps for this nuclear gene were as follows: a 2-min initial denaturation at $94{ }^{\circ} \mathrm{C}$ followed by 35 cycles of $60 \mathrm{~s}$ at $94{ }^{\circ} \mathrm{C}, 30 \mathrm{~s}$ at $45^{\circ} \mathrm{C}, 90 \mathrm{~s}$ at $72{ }^{\circ} \mathrm{C}$ and then a final extension of four minutes at $72^{\circ} \mathrm{C}$. As a second nuDNA marker, we sequenced the intron 4 of the $X$-linked gene BGN using the primers BGN-F and BGN-R (Lyons et al. 1997). Genes linked to sex chromosomes are known to evolve faster than autosomes due to their smaller effective population size. PCRs were carried out for this gene in 20-1L simplex reactions consisting of $2 \mathrm{IL}$ DNA (10 ng/ IL), $2.0 \mathrm{IL}$ 10X PCR buffer without $\mathrm{MgCl}_{2}, 0.8 \mathrm{IL}$ $\mathrm{MgCl}_{2}(1.5 \mathrm{~mm}), 0.16 \mathrm{IL}$ dNTPs $(25 \mathrm{~mm}), 1 \mathrm{IL}$ of each primer (10 IM), $0.12 \mathbf{I L}(1 \mathrm{U})$ Taq DNA polymerase and $\mathrm{ddH}_{2} \mathrm{O}$. Thermocycling consisted of 10-min initial denaturation at $95^{\circ} \mathrm{C}$ followed by 30 cycles of $15 \mathrm{~s}$ at $95^{\circ} \mathrm{C}$, $30 \mathrm{~s}$ at $55^{\circ} \mathrm{C}, 60 \mathrm{~s}$ at $72{ }^{\circ} \mathrm{C}$ and then a final extension of $5 \mathrm{~min}$ at $72^{\circ} \mathrm{C}$. All PCR products were purified and most of them sequenced in both directions using an $\mathrm{ABI} 3100$ automated sequencer (PE Biosystems, Warrington, UK), following the manufacturer's protocols. Sequences from a few samples were obtained after repeating the sequencing with only the forward primer and several times until the ambiguities could be solved. The molecular sequences generated by this study have been deposited in GenBank under the accession numbers listed in Appendix 1.

\section{Sequence analyses}

The evolutionary relationships within the genus Eptesicus were reconstructed independently from the mtDNA and the nuDNA data set. The Cytb and ND1 fragments and the RAG2 and the BGN genes were concatenated into single sequences respectively following Wiens (1998), and because no highly supported incongruence was found comparing reconstructions from each single marker (Figs S1 and S2). In fact, both mtDNA markers produced the same clusters with almost identical internal relationships, whereas the differences in the two nuDNA markers were clearly associated with differences in resolution between the genes, being RAG2 more conserved and leaving unsolved many terminal groupings (Figs S1 and S2). All reconstructions were rooted with the species Myotis myotis and/or M. schaubi from the closer and recently recognized by subfamily Myotinae (Hoofer \& Van Den Bussche 2003).

For both mtDNA and nuDNA data set phylogenetic, hypotheses were obtained using three optimality criteria: maximum parsimony (MP), maximum-likelihood (ML) and 
Bayesian posterior probabilities (BPP). MP phylogenetic analyses were conducted using PAUP* 4.0b10 (Swofford 2001), ML analyses were implemented in PhyML (Guindon \& Gascuel 2003) and BPP were performed in MrBAYES v. 3.1.2. (Huelsenbeck \& Ronquist 2001). Under MP, trees were obtained after heuristic search with an initial tree obtained by stepwise addition (random input order) of the taxa, followed by a complete tree-bisection-reconnection (TBR) branch swapping. This process was repeated 25 times. Topologies were obtained both by unweighting changes and differentially weighting transversions according to likelihood estimates of ts/tv ratios for each data set to take into account the heterogeneity of the sequences. The robustness for each topology was then assessed through bootstrapping (Felsenstein 1985) after 2000 iterations. In both (mtDNA and nuDNA) data set, complex models were selected using the Akaike information criterium implemented in JMODELTEST 0.1 (Posada 2008). Accordingly, for the following analyses (MLs and BPPS), substitution models were used with all parameters allowed to vary and empirically estimated. Under ML, trees were obtained using PhyML fast algorithm (Guindon \& Gascuel 2003) implemented on line (http://www.atgc-montpellier. fr/phyml) to perform Nearest Neighbour Interchanges (NNIs) and using a BIONJ distance-based tree as starting trees. Bootstrap values were obtained after 1000 replicates. The BPPs were obtained with random starting trees without constraints and the data set partitioned: (i) by character position (six partitions) allowing specific rates to vary across sites and (ii) by gene (two partitions), being in this case, model parameters estimated independently for each fragment. For both designs, the Bayesian topologies that were obtained after five simultaneous Markov chains were run for 3 million generations; trees were sampled every 300 generations. The resulting burn-in values were determined empirically after likelihood scores reached stationary values. Analyses were repeated in two separate runs to ensure that trees converged on the same topology and similar parameters. The best-fitting partitioning model was chosen estimating the Bayes factor (BF) between the two alternatives and for each data set. We calculated the BFs using the differences between the harmonic mean $(\mathrm{HM})$ of the likelihood scores from each posterior distribution as an approximation to the differences between marginal likelihoods. According to Pagel \& Meade (2006), a BF value $>10$ was considered as strong support of the alternative model.

The genetic differentiations within and between groups were estimated according to a Kimura 2-parameter (K2P) model and for the Cytb fragment using MEGA v. 5 (Tamura et al. 2011) to produce a measure of a 'standardized genetic distance' between taxa.
Results

For each fragment, alignments were obtained with SEQUENCHER V. 4.1 (GeneCodes, Corp., Ann Arbor, MI, USA) and inspected visually for ambiguities. Due to differences in the quality of the DNA related to the variety of conservation conditions and origins, amplification success varied greatly among samples. Therefore, mtDNA sequences were trimmed for each marker to a fragment in which peaks could unequivocally be assigned for all individuals. Neither incongruent sequences or stop-codon/indels (indicating possible nuclear copies) nor double peaks (evidencing heteroplasmy) were found in the selected fragment for any sequence. In non-coding sequences, indels were corrected manually to minimize alignment gaps. A unique 234-bp insertion present only in the BGN fragment of $E$. anatolicus was excluded from the alignment to avoid possible homology uncertainty (Dool et al. in press).

In the final mtDNA alignment, and to avoid losing significant lineages, the sequences of the Cytb and ND1 genes were trimmed to a length of $755 \mathrm{bp}$ and $665 \mathrm{bp}$ respectively for a total of 120 sequences (see Appendix 1). The combined alignment consisted of 1420 positions of which 742 characters were constant, 65 parsimony uninformative and 613 parsimony informative. The equally weighting MP heuristic search retained seven equally mostparsimonious trees of 3402 steps (first tree: $\mathrm{Cl}=0.31$; $\mathrm{HI}=0.69 ; \mathrm{RI}=0.83$ ). Down-weighting transitions (1:9), the search produced 12 best trees of 2900 steps (first tree $\mathrm{Cl}=0.57 ; \mathrm{HI}=0.42 ; \mathrm{RI}=0.91$ ). Both MP designs recovered a similar consensus topology with also similar bootstrap values, although slightly higher when weighting transversions. Consequently, the results of down-weighting transitions are the only presented (Fig. 3). ML topology (not shown) was very similar to the BPP approach and produced the lowest node supports (as expected). With respect to the BPP approach, both partition designs reached stationarity after 400000 generations. Consensus trees showed almost identical topology, but according to the BF ratio, partition by character $(\mathrm{HM}=-15821.65)$ was selected against partition by gen ( $\mathrm{HM}=-15887.71)$. The mtDNA topologies inferred by the MP, ML and BPP criteria were basically identical. The only main disagreement was regarding the relative positions of $\mathrm{E}$. isabellinus and the American group, which switched positions according to the analysis at the base of a single large Eptesicus group (Fig. 3).

In the final nuDNA alignment, the complete RAG2 gene (1054 bp) and the BGN intron (550 bp) were assembled for a total of 80 individuals (see Appendix 1). Heterozygote positions were treated as ambiguities and gaps as a fifth state; stop-codons were not found in any sequence. The concatenated alignment consisted of 1604 positions, of 


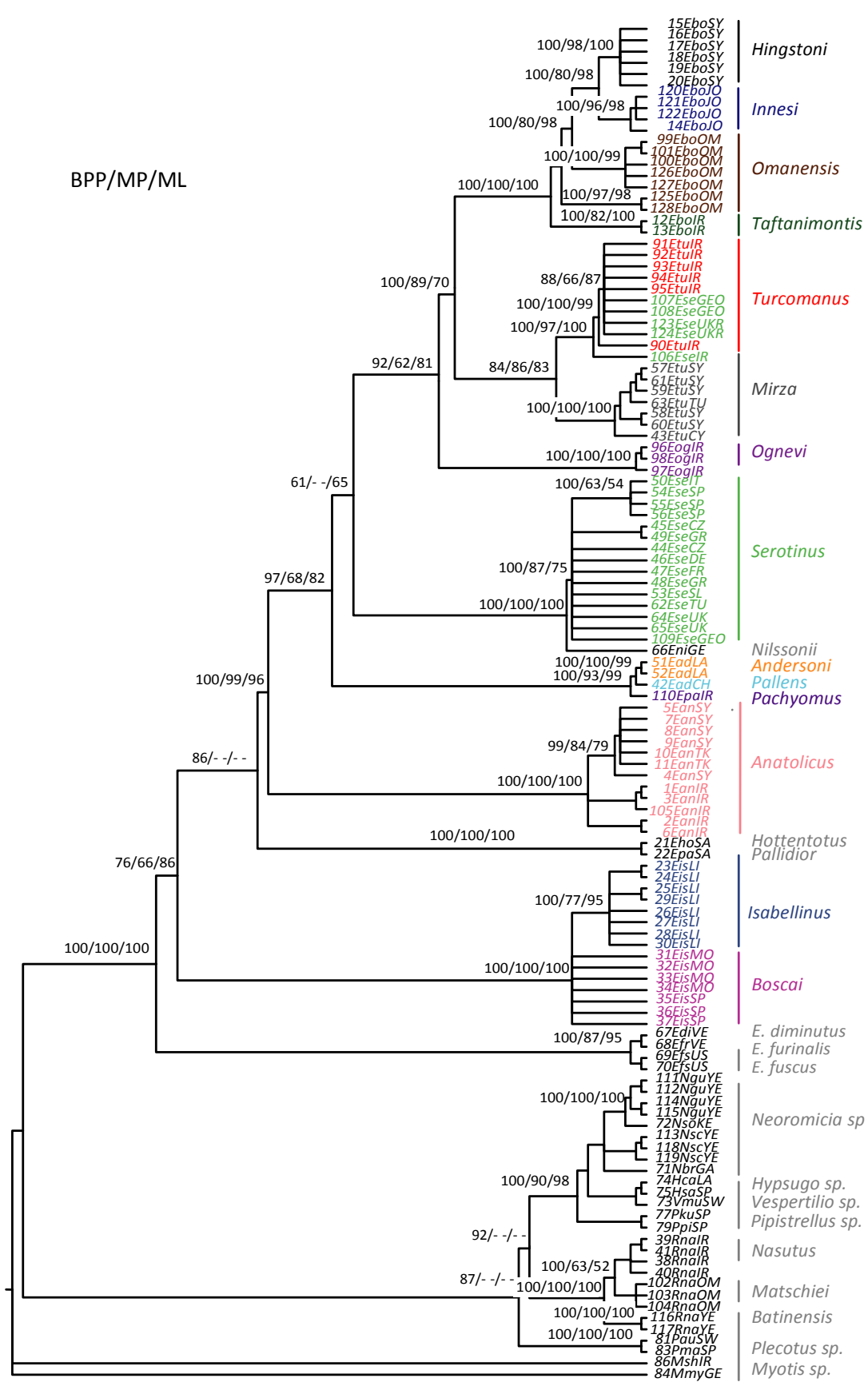

Fig. 3 Phylogenetic relationships of the Old World studied taxa of the genus Eptesicus based on concatenated mtDNA Cytb and ND1. The reconstruction presented is a Bayesian consensus tree with proportionally transformed branches allowing specific model rates to vary across characters. Above-selected nodes and from left to right: Bayesian posterior probabilities (BPP) partitioning the data set by character, bootstrap values from the Maximum Parsimony (MP) analysis weighting 9:1 transversions over transitions and bootstrap values from a Maximum-Likelihood (ML) analysis after 1000 iteractions.

which 1050 characters were constant and 366 were variable and parsimony informative. The equally weighting MP heuristic search retained 1257 equally most-parsimonious trees of 965 steps (first tree: $\mathrm{Cl}=0.72 ; \mathrm{HI}=0.28$;
$\mathrm{RI}=0.64)$. Down-weighting transitions (1:2), the search produced 145 best trees of 737 steps (first tree $\mathrm{Cl}=0.85$; $\mathrm{HI}=0.14 ; \mathrm{RI}=0.94)$. Again, when down-weighting transitions, MP hypotheses were more robust and these results 
are the only ones presented (Fig. 4). ML and BPP criteria produced similar topologies with lower nodes' support in the ML, particularly at the internal structure. Regarding the BPP approach, both designs reached stationarity after 300000 generations. Consensus trees showed almost identical topology, and again according to the BF ratio, partition by character $(\mathrm{HM}=-7133.80)$ was selected against partition by gen $(\mathrm{HM}=-7364.92)$. All nuDNA topologies showed a deep split of a large 'serotinus group' differentiated from a 'bottae group' (Fig. 4). In fact, the topologies originated from both mtDNA and nuDNA data set disagree notably also at the tip groups and their internal relationships. For instance, the definition and relationships of the 'turcomanus' samples group, the resolution was higher at the basal portion of the trees in the nuDNA-based reconstructions, particularly under the MP criterion.

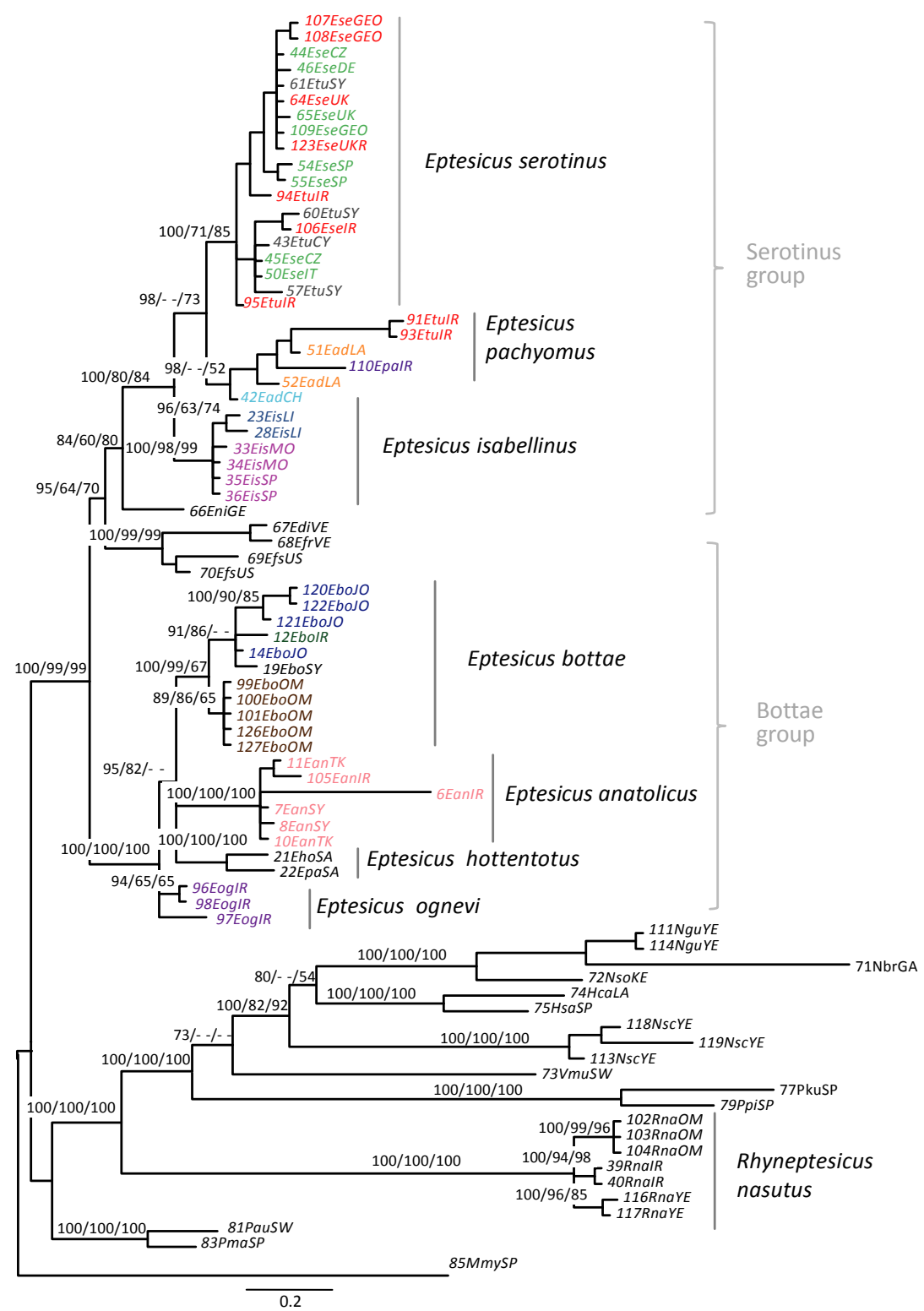

Fig. 4 Phylogenetic relationships of the studied Old World taxa of the genus Eptesicus based on concatenated fragments of the nuclear RAG2 and BGN genes. The species taxonomic arrangement proposed within the genus is indicated at the right side. The reconstruction presented is a Bayesian consensus tree allowing specific model rates to vary across characters. Above-selected nodes and from left to right: BPP partitioning the data set by character, bootstrap values from the Maximum Parsimony (MP) analysis weighting 3:1 transversions over transitions, and bootstrap values from a Maximum-Likelihood (ML) analysis after 1000 iteractions. 
Table 1 Summary of the support shown by each data set and final taxonomic proposal for each of the different Old World forms studied within the genus Eptesicus

\begin{tabular}{|c|c|c|c|c|}
\hline Form & Morphology & mtDNA & nuDNA & Taxonomic proposal \\
\hline hingstoni Thomas, 1919 & $x$ & $x$ & $\mathrm{x}$ & E. bottae hingstoni \\
\hline innesi (Lataste, 1887) & $\mathrm{x}$ & $\mathrm{x}$ & $\mathrm{x}$ & E. bottae innesi \\
\hline omanensis Harrison, 1976 & $x$ & $x$ & $\mathrm{x}$ & E. bottae omanensis \\
\hline taftanimontis de Rouguin, 1988 & $x$ & $x$ & $x$ & E. bottae taftanimontis \\
\hline ognevi Bobrinskii, 1918 & $x$ & $X^{\star \star}$ & $x$ & E. ognevi \\
\hline anatolicus Felten, 1971 & $\mathrm{x}$ & $X^{* \star}$ & $x$ & E. anatolicus \\
\hline serotinus (Schreber, 1774) & $\mathrm{x}$ & $x$ & $x$ & E. serotinus \\
\hline turcomanus Eversmann, 1840 & $\mathrm{x}$ & $\mathrm{x}$ & - & E. serotinus (=turcomanus) \\
\hline mirza de Filippi, 1865 & - & $x$ & - & E. serotinus mirza \\
\hline pachyomus Tomes, 1857 & $x$ & $x$ & $x$ & E. pachyomus \\
\hline andersoni Donson, 1871 & $?$ & $x$ & - & E. pachyomus andersoni \\
\hline pallens Miller, 1911 & $?$ & $\mathrm{x}$ & $x^{*}$ & E. pachyomus pallens? \\
\hline isabellinus Temminck, 1840 & $x$ & $x$ & $x$ & E. isabellinus \\
\hline boscai Cabrera, 1904 & ? & $x$ & $x^{*}$ & E. isabellinus boscai \\
\hline hottentotus (A. Smith, 1833) & $x$ & $x$ & $x$ & E. hottentotus \\
\hline pallidior Shortridge, 1942 & $x$ & $x$ & - & E. hottentotus pallidior \\
\hline nasutus (Dobson, 1877) & $x$ & $\mathrm{x}$ & $x$ & Rhyneptesicus nasutus \\
\hline matschiei Thomas, 1905 & $\mathrm{x}$ & $x$ & $x$ & Rhyneptesicus nasutus matschiei \\
\hline batinensis Harrison, 1968 & $x$ & $x$ & $x$ & Rhyneptesicus nasutus batinensis \\
\hline
\end{tabular}

*X No total agreement among the used reconstructions criteria.

$\star \star \chi$ Possible further cryptic diversity within the taxon.

Remarkably, all mtDNA- and nuDNA-based phylogenies showed that Eptesicus is not monophyletic. All 'nasutus' samples branched off distantly from the rest of Eptesicus which otherwise made a monophyletic clade. The relationships of 'nasutus' remained unresolved in all reconstructions although both mtDNA-based and nuDNA topologies supported a sister relation with a cluster including Hypsugo, Neoromicia, Vespertilio and Pipistrellus basally to the clade of Vespertilionini (Figs 3 and 4).

The mtDNA-based topologies (Fig. 3) indicated a deep grouping structure within the Eptesicus clade that is in general agreement with the recent picture based on morphology (Benda et al. 2006) and supported by most of the geographically based intraspecific subdivisions. Nevertheless, several of these groups were not sustained by the nuDNA dataset. For instance, whereas the morphologically defined turcomanus and mirza groups were clearly supported by the mtDNA data set (Fig. 3), nuDNA did not support this arrangement and allocated all turcomanus and mirza specimens sparse and mixed within a group morphologically identified as serotinus or located even farther along the trees (Fig. 4). The turcomanus + mirza clade joined in all the mtDNA topologies a cluster that morphologically corresponds to 'bottae' and which showed a clear geographical structure distinguishing four groups corresponding to the samples from Syria, Jordan, Oman and Iran, respectively. The 'bottae group' and its subdivisions were clearly supported also by the nuDNA-based topologies and related to a group including all the specimens identified morphologically as ognevi. The mtDNA analysis placed the 'ognevi' specimens as a sister group to bottae and 'turcomanus + mirza'. In fact, the nuDNA hypotheses joined 'ognevi' and 'bottae' in the well-supported 'bottae group' which also included the group 'anatolicus'. The latter is another monophyletic group well supported by both mtDNA and nuDNA data sets from Turkey, Syria and Iran.

All Western European 'serotinus' bats clustered with some Eastern samples in a monophyletic group in the mtDNA-based topologies. These were closely attached to the much smaller E. nilssonii, but apart from other 'serotinus' from Georgia, Iran and Ukraine. Instead, the nuDNAbased topologies grouped all western and eastern 'serotinus' in a well-supported monophyletic group which included also the specimens morphologically identified as 'turcomanus' and/or 'mirza'. The nuDNA-based topologies placed E. nilssonii in a position distant from this cluster. Other groups identified in the mtDNA-based reconstructions included: (i) a clade constructed from serotine samples from China and Laos and including, interestingly enough, a sample corresponding morphologically to the taxon 'pachyomus' from Iran, (ii) an Afrotropic 'hottentotus' group from South Africa and (iii) an 'isabellinus' cluster which showed a further differentiation of the specimens from Libya. The nuDNA also supported these last groupings but with a better defined topological structure. In fact, the 
Far East clade (now including 'pachyomus' and specimens from Iran) and 'isabellinus' appeared as part of the 'serotinus group' which is linked to an American cluster. Interestingly, the other African species appeared, instead, as part of the other supra-specific 'bottae group'.

\section{Discussion}

The joint analyses of morphology, mtDNA- and nuDNAbased phylogenetic reconstructions suggest a number of important changes in the traditional view of the genus Eptesicus (Table 1) and its phylogenetic relationships:

The taxonomic status of Eptesicus nasutus

Our analyses confirm the close relationships between the tribes Vespertilionini and Pipistrellini as defined by Hoofer \& Van Den Bussche (2003) within the subfamily Vespertilioninae. These results also indicate a close phylogenetic relationship between the nasutus samples and these tribes, and a distant relationship from the other Eptesicus, which, according to Hoofer \& Van Den Bussche (2003), belong to the tribe Nycticeini. In fact, nasutus appears in the topologies associated with other genera that were once related to Eptesicus, but that are currently separated (e.g. the Australian Vespadelus or the Afrotropic Neoromicia). These topologies indicate that the 'nasutus' group cannot be included in Eptesicus, but belongs instead to a different genus whose close evolutionary relationships are still unclear (Figs 3 and 4). An available name for this taxon is Rhyneptesicus, a name that Bianchi (1917) proposed to distinguish nasutus on the basis of a lack of an epiblema as a diagnostic character. Although all nasutus used for this study have epiblema, (thereby indicating that this diagnostic character is not valid), the formal description and name are still applicable. In fact, Rhyneptesicus was recovered as a genus by Horáček \& Hanák (1986) and as a subgenus by Horáček et al. (2000). The valid morphological characters which differentiate this genus are the relatively narrow pointed ears, long tragus and relative short fur. There are also dental characters that support this distinction such as the unicuspidal first upper incisor and the complete molar including protocrista. Rhyneptesicus has the typical baculum morphology of the Eptesicus (Hill \& Harrison 1987), but the structure of its karyotype is still unknown. Both mtDNA and nuDNA markers indicate a strong and geographically sound genetic structure within its discontinuous distribution. Taxonomically, the reconstructions validate subspecific recognition for the nominal nasutus from the samples of Iran, close to the terra typica in Pakistan plus the forms matschiei (for Yemeni specimens) and batinensis from Oman. This arrangement is also supported by values of K2P-corrected distances of 3.36 and $6.55 \%$ between them (Table S1).
The genus Eptesicus and the American clade

Apart from the nasutus samples, all Eptesicus from the different continents cluster in the analyses in a well-supported basal group (Figs 3 and 4) sustaining the monophyly of the clade and its taxonomic validity. The genus Eptesicus Rafinesque, 1820 is well defined on the basis of a series of morphological characters such as absence of the $\mathrm{pm}^{2}$, myotodont lower molars, well-defined basisphaenoidal pits, a triangular-shaped baculum and a $2 n=50 / N F=48$ karyotypic formula (Heller \& Volleth 1984; Horáček \& Hanák 1986; Hill \& Harrison 1987; Morales et al. 1991). Recent molecular studies have placed the genus Eptesicus in the tribe Nycticeini and separated it from the pipistrelles (Hoofer \& Van Den Bussche 2003; Hoofer et al. 2006). In their comprehensive study of the family Vespertilionidae, these authors also found that the American Eptesicus and the genus Histiotus form a unique American clade, which makes the American Eptesicus paraphyletic with respect to the Old World members of the genus. To resolve this situation they suggest relegating Histiotus to subgeneric rank and propose restoring the name Cnephaeus to include the Old World forms, as a subgenus. We support this option for the sake of taxonomic stability because it will bring less turmoil to the taxonomy of the Palaearctic forms.

All American species of Eptesicus included in our analyses cluster in a monophyletic group that corresponds to the American clade suggested by Hoofer \& Van Den Bussche (2003); Hoofer et al. (2006) and Roehrs et al. (2010). This would indicate that a single penetration event of Eptesicus has occurred from one continent to another. The oldest fossil records of Eptesicus in North America correspond to Early Upper Miocene (Czaplewski \& Morgan 2003). This date coincides also with the estimated dating of the American split of the bats of the genus Myotis whose diversification has been related to the global cooling and the development of temperate conditions during this period (Stadelmann et al. 2004, 2007). Finally, our results also show a small degree of differentiation (both at nuDNA and mtDNA) found between the small American Eptesicus species $E$. furinalis and $E$. diminutus. A molecular review of these taxa seems particularly needed.

Taxonomic inferences of Palaearctic forms

The classical taxonomic arrangements (Gaisler 1970; Harrison 1975; Nader \& Kock 1990; Horáček et al. 2000) have considered that the systematics of the Palaearctic Eptesicus revolved around two main species: the smaller $\mathrm{E}$. bottae and the larger E. serotinus, to which most of the described forms have been ascribed either as subspecies (e.g.'turcomanus') or synonymized (e.g. 'intermedius'). This basal division in two main groups is supported by all our nuDNA-based topologies (Fig. 4). 
The 'bottae group'

Within the small bats grouped in the 'bottae group', our analyses support E. bottae as a valid monophyletic entity at specific level although showing some differences in composition and structure from previously suggested groupings (e.g. Harrison 1975; Nader \& Kock 1990). The deep molecular structure found in mtDNA and nuDNA trees coincides with its consideration of the species as formed by discontinuous populations morphologically differentiated on the basis of pelage colour and size. The patchy distribution may be related to the fact that inhabits oases and relatively humid areas in a variety of extreme arid habitats along the edge of the southern Palaearctic (Nader \& Kock 1990). The nuDNA analyses support the distinction of the following taxa: (i) ' innesi' from Sinai, the outskirts of Cairo, southern parts of Israel and Jordan and related to, (ii) ' hingstoni' found from Syria all the way to south-eastern Iraq, (iii) ' taftanimontis' from Kerman and Baluchestan provinces of south-eastern Iran and (iv) ' omanensis', apparently linked to mountains and high altitudes of north-eastern Oman (Harrison 1975) and this being the most distinct morphologically. All these forms are tentatively maintained as subspecies within bottae, as recognized by Nader \& Kock (1990), but need confirmation in relation to the rare nominotypical form of E. bottae which could not be included in our analysis.

The species E. ognevi Bobrinskoj, 1918 also stands in the mtDNA-based analyses as a well-defined group also supported by the nuDNA analyses, which include 'ognevi' clearly within the 'bottae group'. The large differentiation shown by one of the samples (97EogIR) suggests further cryptic differentiation within the clade. This pale little form from deserts and steppes of the northern part of the Middle East was described from Western Tajikistan and soon after its description was synonymized with sodalis and later included within E. bottae (Hanák \& Gaisler 1971; Harrison 1975; Nader \& Kock 1990; Artyushin et al. 2009). In contrast to other recent examples of newly recognized species, for example within Otonycteris (Benda \& Gvoždík 2010), morphological differences between bottae and ognevi are very subtle.

Both our mtDNA- and nuDNA-based results validate also E. anatolicus Felten, 1971 as a fully distinct species. This taxon was originally described from south-western Anatolia based on external (e.g. pelage coloration) and skull characters (e.g. high braincase), and was later included within E. bottae (Harrison 1975). However, it was recognized as the most distinct form within E. bottae and vindicated as probably valid species by Hanák et al. (2001) and Benda et al. (2006), who also pointed new ecological differences with respect to E. bottae. Contrary to E. bottae, E. anatolicus seems to be a Mediterranean forest-related species with echolocation calls that are also quite different from those of E. bottae: peak frequency of $28 \mathrm{kHz}$ in E. anatolicus (von Helversen 1998) against $32.5 \mathrm{kHz}$ in E. bottae (Holderied et al. 2005). Our results suggest a close phylogenetic relationships between $\mathrm{E}$. anatolicus and both E. bottae and E. ognevi within the group. E. anatolicus represents a rather common faunal element throughout the Mediterranean forests of the Levantine Sea from Rhodes (Greece) and Cyprus in the west to southern Anatolia and Lebanon in the south-east, north-western Syria and western Iran. It avoids open xeric areas and reaches southwards as far as Kerman (Spitzenberger 1994; von Helversen 1998; Benda et al. 2006, 2007). A recent mtDNA-based revision of Palaearctic bat species has also supported this specific consideration (Mayer et al. 2007), although the mtDNA internal structure and the large differentiation shown by one of the samples (6EanIR) suggest again further cryptic differentiation within the clade.

The two E. hottentotus samples stand as another very distinct group. The taxonomy of the different forms described within E. hottentotus is still confused and requires further research. The two forms included in our analysis, hottentotus and pallidior, were synonymized in the most recent morphological revision by Schlitter \& Aggundey (1986). Our molecular analyses indicate that our hottentotus sample from Cape Province is highly differentiated (over 12\% K2P distance in the Cytb, Table S1) from the sample pallidior from Goodhouse, near the border with Namibia and found in xeric 'karoo' habitats. Probably related to these habitat differences, pallidior is much paler than E. hottentotus (M. Ruedi, pers. comm.). Therefore, we validate the form pallidior Shortridge, 1942 and recognize it at least as a valid subspecies that would extend through north-western Cape and Namibia. Its final taxonomic consideration needs more thorough studies that will probably raise this taxon to specific rank. This Ethiopian clade appears basal to the rest of the 'bottae group' and distant from the larger African 'isabellinus' which belongs to the 'serotinus group'. Thus, the hypothesis that there is an African monophyletic lineage within Eptesicus is not supported.

The 'serotinus group'

Morphologically, there are three forms closely related to 'serotinus': one large, normally pale, known as 'mirza' (Turkey, South Iran, Levant, Cyprus); a second medium sized, dark, corresponding to the nominal 'serotinus' (Europe, Anatolia and Caucasus); and finally, a small, with 'sandy' fur colour and pale-face form (Strelkov \& Iljin 1992; Benda et al. 2006) known as 'turcomanus' (central Asia and northeast Iran). Both mtDNA and nuDNA support clades identified morphologically as 'serotinus' (Figs 3 and 4), but interestingly the composition and structure of this clade 
vary significantly according to the markers. The mtDNAbased reconstructions show two paraphyletic groups of 'serotinus' samples (Fig. 3), one made up by all Western European samples clustering together with E. nilssonii as distinct from another group made of 'serotinus' from Ukraine, Georgia and Iran together with 'turcomanus'. This clade is connected with the samples from Syria, Turkey and Cyprus that morphologically correspond to 'mirza'. In summary, the mtDNA distinguishes three lineages within 'serotinus' one linked to E. nilssonii, another that groups 'serotinus' and 'turcomanus' morphotypes and another that corresponds to 'mirza'.

The nuDNA hypotheses invalidated the three groups because all its members appear now sparse in a well-supported unique clade corresponding to E. serotinus (Schreber, 1774), which is now located far apart from E. nilssonii (Fig. 4). According to these reconstructions, it seems appropriate to keep only mirza as $s$ subspecies within E. serotinus. The form 'turcomanus' would be included in and synonymized within E. serotinus despite its morphological differences which are not supported by any marker. Similar results are obtained by Artyushin et al. (2012) using other nuclear markers. Neither is the third mtDNA lineage validated because it seems linked to a mitochondrial capture by other species (see below). Within this definition, E. serotinus extends its distribution from England and Western Iberia to Central Asia (Benda et al. 2006).

The Eptesicus samples from the Far East (Laos and China) are distinguished from the 'serotinus group' in a well-supported clade in both mtDNA- and nuDNA-based analyses (Figs 3 and 4). Although the whole lineage clearly needs further research, the level of differentiation shown in all markers supports the species rank of this Oriental lineage that comprises Far Eastern as well as Indian forms. The samples from the Far East cluster in all topologies with two samples identified morphologically as well as by mtDNA as turcomanus from Iran plus another sample from Southern Iran (Dehbarez). Contrary to the former, this last sample was obtained from a bat with a pale face and brownish grey (not dark) dorsal pelage with whitish tips. All these characters indicate closer relationships with the Indian forms and accordingly it was identified as pachyomus. The topologies suggest thus an evolutionary connection between the two lineages. The levels of genetic differentiation within the clade validate taxonomically the forms 'andersoni' (Dobson, 1871) described from Yunnan, southern China and 'pallens' (Miller, 1911) from central China. According to our rank topologies, they are tentatively considered as subspecies of E. pachyomus (Tomes, 1857) because this last one has priority on the other two names. Genetic analyses have supported species rank for other extreme Oriental forms of Palaearctic bats such as Barba- stella (Zhang et al. 2007) and Nyctalus (Salgueiro et al. 2007), which were once considered as part (or at best as subspecies) of extremely widespread morphologically uniform units.

E. isabellinus (Temminck, 1840) stands out as a clearly differentiated clade both in mtDNA- and nuDNA-based reconstructions (Figs 3 and 4). Originally described from Libya (type locality outskirts of Tripoli) and distributed across north-west Africa, it was traditionally included in E. serotinus as well as more recently (Simmons 2005), although it was vindicated as a species by other authors (e.g. Benda et al. 2004). Previous studies have supported its species rank and extended its distribution to the southern half of the Iberian Peninsula (Ibánez et al. 2006; Mayer et al. 2007; García-Mudarra et al. 2009). The large mtDNA differentiation (over 13\% K2P distances in Cytb, Table S1) with E. serotinus indicates a long independent evolutionary history despite the extraordinary morphological similarity between the two taxa. In all trees, all $E$. isabellinus from western Libya appears forming a supported clade, whereas samples from Morocco and Iberia in the West appear mixed in MP and ML mtDNA analyses forming another clade which is not fully supported in other analyses. The lack of differentiation between Iberian and Moroccan samples supports the finding (García-Mudarra et al. 2009; Juste et al. 2009) that the Straits of Gibraltar does not act as a geographical barrier for the species. The available name for the western form would be 'boscai', Cabrera, 1904 from Muchamiel, Alicante (Spain) that will include the Moroccan and Iberian populations. The discontinuity in North Africa between the two clades needs a more comprehensive study, including samples from Algeria and/or Tunisia.

Evolutionary remarks from Morphology, mtDNA and nuDNA contrasting patterns

Sequence characteristics, such as the absence of stopcodons or indels and the high degree of congruence in the topologies of the two relatively distant mtDNA fragments (Fig. S1), allow assuming for this study that the discrepancies between mtDNA and nuDNA reconstructions result from actual different histories and are not resulting from molecular or analytical artefacts. The response of a molecular marker to an evolutionary process depends on intrinsic characteristics (e.g. mutation rate, effective population size, selection regime, etc.) and other stochastic processes acting on the whole genome such as genetic drift or bottlenecks; frequently, non-hierarchical processes like introgression further complicate the patterns (Edwards \& Bensch 2009). The different responses imply different evolutionary pathways for each marker, and whether they represent or not the histories of the relevant species will depend on the interplay of these forces (Zhang \& Hewitt 2003). By 
increasing the number of markers studied, we will also increase the chances of recovering evolutionary processes and of reconstructing the complete organismal history (Edwards et al. 2005), facilitating the inference of stable taxonomies. On the other hand, mtDNA-based historical reconstructions maybe partial (Ballard \& Whitlock 2003) and by contrasting mtDNA- and nuDNA-patterns, we can get relevant information about the underlying evolutionary processes (e.g. Wiens et al. 2010; Toews \& Brelsford 2012) due to their deep evolutionary differences, particularly the rapid attainment of reciprocal monophyly of mtDNA genes relative to nuDNA ones (Edwards et al. 2005). In our analyses, besides the differences clearly due to the higher resolution at the deep nodes of nuDNA in relation to mtDNA (e.g. the distinction of the 'serotinus and bottae groups'), the main disagreement between the mtDNA and the nuDNA topologies resides in the relative positions of E. serotinus and $\mathrm{E}$. nilssonii and in the recognition of the turcomanus clade. In the first case, our mtDNA results are in agreement with Artyushin et al. (2009) who have already shown, with a larger geographical coverage, the presence of two clearly distinct mtDNA lineages within E. serotinus, one almost identical to E. nilssonii and the other clearly distinct. The contrasting distant relationship between the two species in our nuDNA-based topologies supports the hypothesis of a mitochondrial introgression and capture of E. nilssonii's mtDNA by E. serotinus. This hypothesis was first suggested by Mayer \& von Helversen (2001) and later supported by Artyushin et al. $(2009,2012)$. According to the model presented by Currat et al. (2008), hybridization would have occurred asymmetrically between front populations of E. serotinus and the resident (or earlier arrived) populations of E. nilssonii, a more cold-tolerant species, during the expansion of E. serotinus west and northwards to new opened suitable habitats. In the expansion along more mesic areas, the captured E. nilssonii's mtDNA would have been transmitted to all present Western populations of E. serotinus, whereas the nuclear imprint of this hybridization event would have been diluted due to demographic factors (Currat et al. 2008). Asymmetrical hybridization with mtDNA capture has been convincingly demonstrated for other European bats of the genus Myotis Kaup, 1829 (Berthier et al. 2006) and more recently for Asian Rhinolophus (Mao et al. 2010) or the African Scotophilus (Vallo et al. 2012).

The second disagreement concerns the morphologically distinct lineages related to E. serotinus. This morphological variability is probably associated with the regional mosaic of habitats in the Middle East from diverse forests with open dry steppes and xeric habitats that point to a scenario of distinct populations isolated in different degrees during climatic cycles and possibly under different selective pres- sures. Secondary contacts during expansion episodes would have allowed for the homogenizing of the nuDNA of these not completely isolated ecomorphs and even the mtDNA in the case of the 'turcomanus'. The differentiation of into desert/mesic ecomorphs has probably evolved several times under different cycles of environmental conditions, as suggested by the large mtDNA differentiation (circa 5\% K2P distance, Table S1) between serotinus + turcomanus and mirza. Several examples of similar partial differentiation in ecomorphs are known, for instance, within the Pipistrellus complex, remarkably also around the Mediterranean basin (Hulva et al. 2010). The morphologically similar species E. fuscus in North America shows also strong concordance between morphological ecomorphs and mtDNA lineages in a complex that maintains high levels of nuDNA flow (Turmelle et al. 2011).

In summary, the net effects of past climate changes on the range of a species are largely determined by the consequences of these changes on its habitat requirements and its physiological tolerances (Hoskin et al. 2011). The evolution, in this case, of the ecologically plastic Palaearctic Eptesicus seems to be determined by the processes of fragmentation, contraction and range expansion that occurred in an area with highly variable geography, in which ecological conditions have changed dramatically in the recent cold/warm climatic cycles (Carrión et al. 2011). In fact, since at least Early to Middle Pleistocene, changes in vegetation during cold periods, leading to the fragmentation of forested landscapes and the development of open dry landscapes, were a general feature of the Mediterranean region and Western Asia (Leroy et al. 2011). The full understanding of the impact of these changes on the evolution of the Palaearctic Eptesicus and the relative contribution of the possible shaping forces (e.g. maternal phylopatry, local selection, etc.) need a more inclusive sampling (at the population level) as well as complementary information provided by additional molecular markers (e.g. Turmelle et al. 2011). Still, our integrative approach of morphological and molecular data has allowed us (Table 1), in this most entangled group of bats, to recover the genus Rhyneptesicus, and redefine E. serotinus and E. bottae. We also confirmed the species rank for $E$. isabellinus and $E$. pachyomus, within a 'serotinus group' and E. ognevi and E. anatolicus within the 'bottae group'.

\section{Acknowledgements}

The authors are very grateful to J. A. Garrido, E. Migens, J. Nogueras and C. Ruíz for their help with the fieldwork. H. Baagoe, A. Guillén, R. Baker, A. Karataş, J. F. Noblet, M. Ruedi, S. Rossiter and D. Scaravelli were generous enough to help us with the sampling. M. Ruedi improved the discussion of the results and Prof. K. Rylander critically 
read the manuscript and provided valuable editorial and language comments to our English style. Logistical support was provided by Laboratorio de Ecología Molecular, Estación Biológica de Dorana, CSIC (LEM-EBD). This research is part of the projects SAF2006-12784-C02-02/ and SAF2006-12784-C02-01/funded by the Direccion General de Investigación of the Spanish Ministry of Science and Technology and by grants from the Czech Science Foundation (No. 206/09/0888) and the Ministry of Culture of the Czech Republic (DKRVO 2013/14, National Museum, 00023272) to P. Benda.

\section{References}

Artyushin, I. V., Bannikova, A. A., Lebedev, V. S. \& Kruskop, S. V. (2009). Mitochondrial DNA relationships among North Palaearctic Eptesicus (Vespertilionidae, Chiroptera) and past hybridization between common Serotine and Northern bat. Zootaxa, 2262, 40-52.

Artyushin, I., Lebedev, V., Bannikova, A. \& Kruskop, S. (2012). A molecular reappraisal of the taxonomic status of Eptesicus serotinus turcomanus. Vespertilio, 16, 31-42.

Baker, R. J., Porter, C. A., Patton, J. C. \& Van Den Bussche, R. A. (2000). Systematics of bats of the family Phyllostomidae based on RAG2 DNA sequences. Occasional Papers, Museum Texas Tech University, 202, 1-16.

Ballard, J. W. \& Whitlock, M. C. (2003). The incomplete natural history of mitochondria. Molecular Ecology, 13, 729-744.

Benda, P. \& Gvoždík, V. (2010). Taxonomy of the genus Otonycteris (Chiroptera: Vespertilionidae: Plecotini) as inferred from morphological and mtDNA data. Acta Chiropterologica, 12, 83102.

Benda, P., Ruedi, M. \& Aulagnier, S. (2004). New data on the distribution of bats (Chiroptera) in Morocco. Vespertilio, 8, 13-44.

Benda, P., Andreas, M., Kock, D., Lučan, R. K., Munclinger, P., Nová, P., Obuch, J., Ochman, K., Reiter, A., Uhrin, M. \& Weinfurtová, D. (2006). Bats (Mammalia: Chiroptera) of the Eastern Mediterranean. Part 4. Bat fauna of Syria: distribution, systematics, ecology. Acta Societatis Zoologicae Bohemicae, 70, 1329.

Benda, P., Hanák, V., Horáček, I., Hulva, P., Lučan, R. \& Ruedi, M. (2007). Bats (Mammalia: Chiroptera) of the Eastern Mediterranean. Part 5. Bat fauna of Cyprus: review of records with confirmation of six species new for the island and description of a new subspecies. Acta Societatis Zoologicae Bohemicae, 71, 71-130.

Benda, P., Lučan, R. K., Obuch, J., Reiter, A., Andreas, M., Kock D., Bačkor, P., Bohnenstengel, T., Eid, E. K., Ševčík, M., Vallo, P. \& Amr, Z. S. (2010). Bats (Mammalia: Chiroptera) of the Eastern Mediterranean. Part 8. Bat fauna of Jordan: fauna, ecology, echolocation, ectoparasites. Acta Societatis Zoologicae Bohemicae, 74, 185-353.

Benda, P., Hanák, V. \& Červeny, J. (2011). Bats (Mammalia: Chiroptera) of the Eastern Mediterranean. Part 9. Bats from Transcaucasia and West Turkestan in collection of the National Museum, Prague. Acta Societatis Zoologicae Bohemicae, 75, 159222.

Berthier, P., Excoffier, L. \& Ruedi, M. (2006). Recurrent replacement of mtDNA and cryptic hybridization between two sibling bat species Myotis myotis and Myotis blythii. Proceedings of the Royal Society of London B, 273, 3101-3109.

Bianchi, V. (1917). Predvaritel'nyja zametki o letučih' myšah' (Chiroptera) Rossii [Notes préliminaires sur les chauve-souries ou Chiroptères de la Russie]. Ežegodnik Zoologičeskogo Muzeja Akademii Nauk, 21, 73-82 (in Russian, French subtitle).

Bickford, D., Lohman, D. J., Sodhi, N. S., Ng, P. K. L., Meier, R., Winker, K., Ingram, K. K. \& Das, I. (2007). Cryptic species as a window on diversity and conservation. Trends in Ecology and Evolution, 22, 148-155.

Carrión, J. S., Rose, J. \& Stringer, C. (2011). Early human evolution in the Western Palaearctic: ecological scenarios. Quaternary Science Review, 30, 1281-1295.

Currat, M., Ruedi, M., Petit, R. J. \& Excoffier, L. (2008). The Hidden side of invasions: massive introgression by local genes. Evolution, 62, 1908-1920.

Czaplewski, N. J. \& Morgan, G. S. (2003). Fossils bats of the Americas. Available via: <http://www.snomnh.ou.edu/collectionsresearch/cr-sub/ vertpaleo/fossil_bats/index.shtml>.

Degnan, J. H. \& Rosenberg, N. A. (2009). Gene tree discordance, phylogenetic inference and the multispecies coalescent. Trends in Ecology and Evolution, 24, 332-340.

Dool, S. E., Puechmaille, S. J., Dietz, C., Juste, J., Ibánez, C., Hulva, P., Roué, S. G., Petit, E. J., Jones, G., Russo, D., Toffoli, R., Viglino, A., Martinoli, A., Rossiter, S. J. \& Teeling, E. C. (in press). Phylogeography and postglacial recolonisation of Europe by Rhinolophus hipposideros: evidence from multiple genetic markers. Molecular Ecology.

Edwards, S. V. (2008). Is a new and general theory of molecular systematics emerging? Evolution, 63, 1-19.

Edwards, S. V. \& Bensch, S. (2009). Looking forwards or looking backwards in avian phylogeography? A comment on Zink and Barrowclough 2008 Molecular Ecology, 18, 2930-2933.

Edwards, S. V., Kingan, S. B., Calkins, J. D., Balakrishnan, C. N., Jennings, W. B., Swanson, W. J. \& Sorenson, M. D. (2005). Speciation in birds: genes, geography, and sexual selection. Proceedings of the National Academy of Sciences, 102, 65506557.

Felsenstein, J. (1985). Confidence limits on phylogenies: an approach using the bootstrap. Evolution, 39, 783-791.

Gaisler, J. (1970). The bats (Chiroptera) collected in Afghanistan by the Czechoslovak expeditions of 1965-1967. Acta Scientiarum Naturalium Academiae Scientiarum Bohemoslovacae Brno, 4, 1-56.

García-Mudarra, J. L., Juste, J. \& Ibánez, C. (2009). The Straits of Gibraltar: barrier or bridge to the Ibero-Marrocan bats. Biological Journal of the Linnean Society, 96, 434-450.

Guindon, S. \& Gascuel, O. (2003). A simple, fast, and accurate algorithm to estimate large phylogenies by maximum likelihood. Systematic Biology, 52, 696-704.

Hanák, V. \& Gaisler, J. (1971). The status of Eptesicus ognevi Bobrinskij, 1918, and remarks on some other species of this genus (Mammalia: Chiroptera). Věstník Československé Společnosti Zoologické, 35, 11-24.

Hanák, V., Benda, P., Ruedi, M., Horáček, I. \& Sofianidou, T. S. (2001). Bats (Mammalia: Chiroptera) of the Eastern Mediterranean. Part 2. New records and review of distribution of bats in Greece. Acta Societatis Zoologicae Bohemicae, 65, 279-346.

Harrison, D. L. (1975). Scientific results of the Oman Flora and fauna survey, 1975. Description of a new subspecies of Botta's 
serotine (Eptesicus bottae Peters, 1869, Chiroptera: Vespertilionidae) from Oman. Mammalia, 39, 415-418.

Heller, K. G. \& Volleth, M. (1984). Taxonomic position of Pipistrellus societatis Hill, 1972 and the karyological characteristics of the genus Eptesicus (Chiroptera: Vespertilionidae). Zeitschrift fier Zoologische Systematik und Evolutionsforschung, 22, 65-77.

von Helversen, OV (1998). Eptesicus bottae (Mammalia, Chiroptera) auf der Insel Rhodos. Bonner Zoologische Beitrege, 48, 113-121.

Higuchi, R., von Beroldingen, C. H., Sensabaugh, G. F. \& Erlich, H. A. (1988). DNA typing from hairs. Nature, 332, 543-546.

Hill, J. E. \& Harrison, D. L. (1987). The baculum in the Vespertilioninae (Chiroptera: Vespertilionidae) with a systematic review, a synopsis of Pipistrellus and Eptesicus, and the descriptions of a new genus and subgenus. Bulletin of the British Museum (Natural History), Zoology, 52, 225-305.

Hill, J. E. \& Smith, J. D. (1984). Bats. A Natural History (pp. 243). London: The British Museum (Natural History).

Holderied, M. W., Korine, C., Fenton, M. B., Parsons, S., Robson, S. \& Jones, G. (2005). Echolocation call intensity in the aerial hawking bat $\mathrm{E}$. bottae (Vespertilionidae) studied using stereo videogrammetry. Journal of Experimental Biology, 208, 13211327.

Hoofer, S. R. \& Van Den Bussche, R. A. (2003). Molecular phylogenetics of the chiropteran family Vespertilionidae. Acta Chiropterologica, 5, 1-63.

Hoofer, S. R., Van Den Bussche, R. A. \& Horáček, I. (2006). Generic status of the American pipistrelles (Vespertilionidae) with description of a new genus. Journal of Mammalogy, 87, 981992

Horáček, I. \& Hanák, V. (1986). Generic status of Pipistrellus savii and comments on classification of the genus Pipistrellus (Chiroptera, Vespertilionidae). Myotis, 23-24, 9-16.

Horáček, I., Hanák, V. \& Gaisler, J. (2000). Bats of the Palearctic region: a taxonomic and biogeographic review. In B. W. Wołoszyn (Ed.) Proceedings of the VIIIth EBRS. Vol. 1. Approaches to Biogeography and Ecology (pp. 11-157). Kraków: Platan Publication House.

Hoskin, C. J., Tonione, M., Higgie, M., MacKenzie, J. B., Williams, S. E., VanDerWal, J. \& Craig Moritz, C. (2011). Persistence in peripheral refugia promotes phenotypic divergence and speciation in a rainforest frog. The American Naturalist, 178, 561-578.

Huelsenbeck, J. P. \& Ronquist, F. (2001). MrBayes: Bayesian inference of phylogenetic trees. Bioinformatics, 17, 754-755.

Hulva, P., Fornusková, A., Chudárková, A., Evin, A., Allegrini, B., Benda, P. \& Bryja, J. (2010). Mechanisms of radiation in a bat group from the genus Pipistrellus inferred by phylogeography, demography and population genetics. Molecular Ecology, 19, 5417-5431.

Ibánez, C., García-Mudarra, J. L., Ruedi, M., Stadelmann, B. \& Juste, J. (2006). The Iberian contribution to cryptic diversity in European bats. Acta Chiropterologica, 8, 277-297.

Juste, J., Bilgin, R., Muroz, J. \& Ibánez, C. (2009). mtDNA signatures at different spatial scales: from the effects of the Strait of Gibraltar to population structure in the meridional serotine bat (Eptesicus isabellinus). Heredity, 103, 178-187.

Kawai, K., Nikaido, M., Harada, M., Matsumura, S., Lin, L. K., Wu, Y., Hasegawa, M. \& Okada, N. (2002). Intra- and interfamily relationships of Vespertilionidae inferred by various molecular markers including SINE insertion data. Journal of Molecular Evolution, 55, 284-301.

Kearney, T. C., Volleth, M., Contrafatto, G. \& Taylor, P. J. (2002). Systematic implications of chromosome GTG-band and bacula morphology for Southern African Eptesicus and Pipistrellus and several other species of Vespertilioninae (Chiroptera: Vespertilionidae). Acta Chiropterologica, 4, 55-76.

Leroy, S. A. G., Arpe, K. \& Mikolajewicz, U. (2011). Vegetation context and climatic limits of the Early Pleistocene hominin dispersal in Europe. Quaternary Science Reviews, 30, 1448-1463.

Lyons, L. A., Laughlin, T. F., Copeland, N. G., Jenkins, N. A., Womack, J. E. \& O'Brien, S. J. (1997). Comparative anchor tagged sequences (CATS) for integrative mapping of mammalian genomes. Nature Genetics, 15, 47-56.

Maniatis, T., Fritsh, E. F. \& Sambrook, J. (1989). Molecular Cloning: A Laboratory Manual, 2nd edn. Cold Spring Harbor: Cold Spring Harbor Laboratory Press.

Mao, X., Zhang, J., Zhang, S. \& Rossiter, S. (2010). Historical male-mediated introgression in horseshoe bats revealed by multilocus DNA sequence data. Molecular Ecology, 19, 13521366.

Mayer, F. \& von Helversen, O. (2001). Cryptic diversity in European bats. Proceedings of the Royal Society of London B, 268, 1825-1832.

Mayer, F., Dietz, C. \& Kiefer, A. (2007). Molecular species identification boosts bat diversity. Frontiers in Zoology, 4, 4.

Morales, J. C., Scott, C., Ballinger, V., Bickham, J. W., Greenbaum, I. F. \& Schlitter, D. A. (1991). Genetic relationships among eight species of Eptesicus and Pipistrellus (Chiroptera: Vespertilionidae). Journal of Mammalogy, 72, 286-291.

Moratelli, R., Peracchi, A. L., Dias, D. \& de Oliveira, J. (2011). Geographic variation in South American populations of Myotis nigricans (Schinz, 1821) (Chiroptera, Vespertilionidae), with the description of two new species. Mammalian Biology, 76, 592607.

Nader, I. A. \& Kock, D. (1990). Eptesicus (Eptesicus) bottae (Peters 1869) in Saudi Arabia with notes on its subspecies and distribution (Mammalia Chiroptera: Vespertilionidae). Senckenbergiana Biologica, 70, 1-13.

Padial, J. M. \& De la Riva, I. (2010). A response to recent proposals for integrative taxonomy. Biological Journal of the Linnean Society, 101, 747-756.

Padial, J. M., Miralles, A., De la Riva, I. \& Vences, M. (2010). The integrative future of taxonomy. Frontiers in Zoology, 7, 16.

Pagel, M. \& Meade, A. (2006). Bayesian analysis of correlated evolution of discrete characters by reversible-jump Markov chain Monte Carlo. The American Naturalist, 167, 808-825.

Posada, D. (2008). ModelTest: phylogenetic model averaging. Molecular Biology and Evolution, 25, 1253-1256.

Roehrs, Z. P., Lack, J. B. \& Van Den Busshe, R. A. (2010). Tribal phylogenetic relationships within Vespertilioninae (Chiroptera: Vespertilionidae) based on mitochondrial and nuclear sequence data. Journal of Mammalogy, 91, 1073-1092.

Ruedi, M. \& Mayer, F. (2001). Molecular systematics of bats of the genus Myotis (Vespertilionidae) suggests deterministic ecomorphological convergences. Molecular Phylogenetics and Evolution, 21, 436-448.

Salgueiro, P., Ruedi, M., Coelho, M. M. \& Palmeirim, J. M. (2007). Genetic divergence and phylogeography in the genus Nyctalus 
(Mammalia, Chiroptera): implications for population history of the insular bat Nyctalus azoreum. Genetica, 130, 169-181.

Schlitter, D. A. \& Aggundey, I. R. (1986). Systematics of African bats of the genus Eptesicus (Mammalia: Vespertilionidae). 1. Taxonomic status of the large serotines of eastern and southern Africa. Cimbebasia, Ser A, 8, 167-174.

Simmons, N. B. (2005). Order chiroptera. In D. E. Wilson \& M Reeder (Eds) Mammal Species of the World: A Taxonomic and Geographic Reference (pp. 312-529). Baltimore: The Johns Hopkins University Press.

Smith, M. F. \& Patton, J. L. (1993). Diversification of South American muroid rodents: evidence from mitochondrial DNA sequence datafor the Akodontine tribe. Biological Journal of the Linnean Society, 50, 149-177.

Spitzenberger, F. (1994). The genus Eptesicus (Mammalia: Chiroptera) in southern Anatolia. Folia Zoologica, 43, 437-454.

Stadelmann, B., Herrera, L. G., Arroyo-Cabrales, J., FloresMartínez, J. J., May, B. P. \& Ruedi, M. (2004). Molecular systematics of the fishing bat Myotis (Pizonyx) vivesi. Journal of Mammalogy, 85, 133-139.

Stadelmann, B., Lin, K. L., Kunz, T. H. \& Ruedi, M. (2007). Molecular phylogeny of New World Myotis (Chiroptera, Vespertilionidae) inferred from mitochondrial and nuclear DNA genes. Molecular Phylogenetics and Evolution, 43, 32-48.

Strelkov, P. P. \& Iljin, V. J. (1992). Bats of easternmost Europe: distribution and faunal status. In I. Horáček \& V. Vohralík (Eds) Prague Studies in Mammalogy (pp. 193-205). Praha: Charles University Press.

Swofford, D. L. (2001). PAUP*. Phylogenetic Analysis Using Parsimony (*and other methods) Version 4.0b10. Sunderland, MA, USA: Sinauer Associates.

Tamura, K., Peterson, D., Peterson, N., Stecher, G., Nei, M. \& Kumar, S. (2011). MEGA5: molecular evolutionary genetics analysis using maximum likelihood, Evolutionary Distance, and
Maximum Parsimony Methods. Molecular Biology and Evolution, 28, 2731-2739.

Toews, D. \& Brelsford, A. (2012). The biogeography of mitochondrial and nuclear discordance in animals. Molecular Ecology, 21, 3907-3930.

Turmelle, A. S., Kunz, T. H. \& Sorenson, M. D. (2011). A tale of two genomes: contrasting patterns of phylogeographic structure in a widely distributed bat. Molecular Ecology, 20, 357-375.

Vallo, P., Benda, P., Červeny, J. \& Koubek, P. (2012). Conflicting mitochondrial and nuclear paraphyly in small-size West African house bats (Vespertilionidae). Zoologica Scripta, 42, 1-12.

Volleth, M. \& Tideman, C. R. (1989). Chromosome studies in three genera of Australian vespertilionid bats and their systematic implications. Zeitschrift fधr Saugetierkunde, 54, 215-222.

Volleth, M. \& Tidemann, C. R. (1991). The origin of the Australian Vespertilioninae bats, as indicated by chromosomal studies. Zeitschrift fधr S€िugetierkunde, 56, 321-330.

Volleth, M., Bronner, G., Gêpfert, M. C., Heller, K. G., von Helversen, O. \& Yong, H. S. (2001). Karyotype comparison and phylogenetic relationships of Pipistrellus-like bats (Vespertilionidae; Chiroptera; Mammalia). Chromosome Research, 9, 25-46.

Wiens, J. J. (1998). Combining data with different phylogenetic stories. Systematic Biology, 47, 568-581.

Wiens, J. J., Kuckzynski, C. A. \& Stephens, P. R. (2010). Discordant mitochondrial and nuclear gene phylogenies in emydid turtles: implications for speciation and conservation. Biological Journal of the Linnean Society, 99, 445-461.

Zhang, D.-X. \& Hewitt, G. M. (2003). Nuclear DNA analyses in genetic studies of populations: practice, problems and prospects. Molecular Ecology, 12, 563-584.

Zhang, J. S., Han, N. J., Jones, G., Lin, L. K., Zhang, J. P., Zhu, G. J., Huang, D. W. \& Zhang, S. Y. (2007). A new species of Barbastella (Chiroptera: Vespertilionidae) from north China. Journal of Mammalogy, 88, 1393-1403.

Appendix 1 List of specimen acronyms, taxonomic considerations, localities, GenBank accession numbers (Cytb, ND1, RAG2 and BGN) and source of the samples used for the study

\begin{tabular}{|c|c|c|c|c|c|c|c|}
\hline \multirow[b]{2}{*}{ Specimen } & \multirow[b]{2}{*}{ Proposed taxonomy } & \multirow[b]{2}{*}{ Locality } & \multicolumn{4}{|c|}{ GenBank accession no. } & \multirow[b]{2}{*}{ Voucher/source } \\
\hline & & & Cyt b & ND1 & RAG2 & BGN & \\
\hline 1Ean IR & Eptesicus anatolicus & Bisotun, Kermanshah, Iran & EU786802 & EU786926 & - & - & \\
\hline 2Ean IR & Eptesicus anatolicus & Bavineh, Lorestan, Iran & EU786803 & EU786927 & - & - & NMP 48192 \\
\hline 3Ean IR & Eptesicus anatolicus & Qasr-e-Shirin, Kermashah, Iran & EU786804 & EU786928 & - & - & NMP 48193 \\
\hline 4Ean SY & Eptesicus anatolicus & Qala'at Sheisar, Hama, Syria & EU786805 & EU786929 & - & - & NMP 48893 \\
\hline 5Ean SY & Eptesicus anatolicus & Qala'at Sheisar, Hama, Syria & EU786806 & EU786930 & - & - & NMP 48894 \\
\hline 6Ean IR & Eptesicus anatolicus & Deh Bakri, Kerman, Iran & EU786807 & EU786931 & FJ841977 & KF018958 & NMP 48363 \\
\hline 7Ean SY & Eptesicus anatolicus & Baniyas, Hama, Syria & EU786808 & EU786932 & EU786878 & KF018959 & NMP 48900 \\
\hline 8Ean SY & Eptesicus anatolicus & Baniyas, Hama, Syria & EU786809 & EU786933 & EU786879 & KF018960 & NMP 48901 \\
\hline 9Ean SY & Eptesicus anatolicus & Qala'at Marqab, Hama, Syria & EU786810 & EU786934 & - & - & NMP 48918 \\
\hline 10Ean TK & Eptesicus anatolicus & Silifke, Içel, Turkey & EU786811 & EU786935 & EU786880 & KF018961 & Karatas, A. \\
\hline 11Ean TK & Eptesicus anatolicus & Silifke, Astim Caves, Içel, Turkey & EU786812 & EU786936 & EU786881 & KF018962 & Karatas, A. \\
\hline 12Ebo IR & Eptesicus bottae taftanimontis & Bam, Kerman, Iran & EU786813 & EU786937 & FJ841978 & KF018963 & NMP 48114 \\
\hline 13Ebo IR & Eptesicus bottae taftanimontis & Bam, Kerman, Iran & EU786814 & EU786938 & - & - & NMP 48115 \\
\hline 14Ebo J0 & Eptesicus bottae innesi & Wadi Rum, Jordan & EU786815 & EU786939 & EU786882 & KF018964 & NMP 92100 \\
\hline 15Ebo SY & Eptesicus bottae hingstoni & Balis, Halab, Syria & EU786816 & EU786940 & - & - & NMP 48770 \\
\hline 16Ebo SY & Eptesicus bottae hingstoni & Rasafah, Raqqa, Syria & EU786817 & EU786941 & EU786883 & - & NMP 48771 \\
\hline 17Ebo SY & Eptesicus bottae hingstoni & Rasafah, Raqqa, Syria & EU786818 & EU786942 & - & - & NMP 48772 \\
\hline
\end{tabular}


Appendix 1. Continued

\begin{tabular}{|c|c|c|c|c|c|c|c|}
\hline \multirow[b]{2}{*}{ Specimen } & \multirow[b]{2}{*}{ Proposed taxonomy } & \multirow[b]{2}{*}{ Locality } & \multicolumn{4}{|c|}{ GenBank accession no. } & \multirow[b]{2}{*}{ Voucher/source } \\
\hline & & & Cyt b & ND1 & RAG2 & BGN & \\
\hline 18Ebo SY & Eptesicus bottae hingstoni & Dura Europos, Deir ez-Zur, Syria & EU786819 & EU786943 & - & - & NMP 48805 \\
\hline 19Ebo SY & Eptesicus bottae hingstoni & Khazneh, Hassake, Syria & EU786820 & EU786944 & EU786884 & KF018965 & NMP 48818 \\
\hline 20Ebo SY & Eptesicus bottae hingstoni & Khazneh, Hassake, Syria & EU786821 & EU786945 & - & - & NMP 48819 \\
\hline 21Eho SA & Eptesicus hottentotus hottentotus & Algeria Natal Forestry St. South Africa & AJ841963 & EU786946 & EU786885 & KF018966 & Ruedi, M. \\
\hline 22Epa SA & Eptesicus hottentotus pallidior & Goodhouse, South Africa & EU786823 & EU786947 & EU786886 & KF018967 & Ruedi, M. \\
\hline 23Eis LI & Eptesicus isabellinus isabellinus & Leptis Magna, Libya & EU786824 & EU786948 & EU786887 & KF018968 & NMP 49940 \\
\hline 24Eis LI & Eptesicus isabellinus isabellinus & Leptis Magna, Libya & EU786825 & EU786949 & - & - & NMP 49941 \\
\hline 25Eis LI & Eptesicus isabellinus isabellinus & Ar Sharsharah, Tarhunah, Libya & EU786826 & EU786950 & - & - & NMP 49950 \\
\hline 26Eis LI & Eptesicus isabellinus isabellinus & Ar Sharsharah, Tarhunah, Libya & EU786827 & EU786951 & - & - & NMP 49951 \\
\hline 27 Eis LI & Eptesicus isabellinus isabellinus & Nanatalah, Libya & EU786828 & EU786952 & - & - & NMP 49961 \\
\hline 28Eis LI & Eptesicus isabellinus isabellinus & Sabratah, Libya & EU786829 & EU786953 & EU786888 & KF018969 & NMP 49976 \\
\hline 29Eis LI & Eptesicus isabellinus isabellinus & Sabratah, Libya & EU786830 & EU786954 & - & - & NMP 49977 \\
\hline 30Eis LI & Eptesicus isabellinus isabellinus & Sabratah, Libya & EU786831 & EU786955 & - & - & NMP 49979 \\
\hline 31Eis MO & Eptesicus isabellinus boscai & Berkane, Gorge du Zegzel, Morocco & EU786832 & EU786956 & - & - & NMP 90086 \\
\hline 32Eis MO & Eptesicus isabellinus boscai & Berkane, Gorge du Zegzel, Morocco & EU786833 & EU786957 & - & - & NMP 90087 \\
\hline 33Eis MO & Eptesicus isabellinus boscai & Ez Zarka, Yarrhite, Tetouan, Morocco & EU786834 & EU786958 & EU786889 & KF018970 & This paper \\
\hline 34Eis MO & Eptesicus isabellinus boscai & Oued Massa, Morocco & EU786835 & EU786959 & EU786890 & KF018971 & This paper \\
\hline 35Eis SP & Eptesicus isabellinus boscai & Túnel del Picote, Huelva, Spain & EU786836 & EU786960 & EU786891 & KF018972 & This paper \\
\hline 36Eis SP & Eptesicus isabellinus boscai & Puente Canaveroso, Sevilla, Spain & EU786837 & EU786961 & EU786892 & KF018973 & This paper \\
\hline 37Eis SP & Eptesicus isabellinus boscai & Cádiz, Spain & EU786838 & EU786962 & - & - & This paper \\
\hline 38Rna IR & Rhyneptesicus nasutus nasutus & Pir Sohrab, Baluchestan, Iran & FJ841980 & FJ841982 & - & - & This paper \\
\hline 39Rna IR & Rhyneptesicus nasutus nasutus & Pir Sohrab, Baluchestan, Iran & EU786839 & EU786963 & EU786893 & KF018974 & NMP 48405 \\
\hline 40Rna IR & Rhyneptesicus nasutus nasutus & Dehbarez, Hormozgan, Iran & EU786840 & EU786964 & EU786894 & KF018975 & NMP 48437 \\
\hline 41Rna IR & Rhyneptesicus nasutus nasutus & Dehbarez, Hormozgan, Iran & FJ841981 & FJ841983 & - & - & This paper \\
\hline 42Ead $\mathrm{CH}$ & Eptesicus pachyomus pallens & Daguping, nr Foping, Shaanxi, China & EU786841 & EU786965 & EU786895 & KF018976 & NMP 90554 \\
\hline 43Etu $\mathrm{CY}$ & Eptesicus serotinus mirza & Troodos Forest, Kalidonia Trail, Cyprus & EU786842 & EU786966 & EU786896 & KF018977 & NMP 90409 \\
\hline 44Ese CZ & Eptesicus serotinus serotinus & Kolence, South Bohemia, Czech Republic & EU786843 & EU786967 & EU786897 & KF018978 & NMP 90182 \\
\hline 45Ese CZ & Eptesicus serotinus serotinus & Třebíč, Př̃̌stpo, Moravia, Czech Republic & EU786844 & EU786968 & EU786898 & KF018979 & NMP 90183 \\
\hline 46Ese DE & Eptesicus serotinus serotinus & Gredstedbro, Jutland, Denmark & EU786845 & EU786969 & EU786899 & KF018980 & Baagøe, $\mathrm{H}$. \\
\hline 47Ese FR & Eptesicus serotinus serotinus & Châtelus, France & EU786846 & EU786970 & - & - & Noblet, J.F \\
\hline 48Ese GR & Eptesicus serotinus serotinus & Kombotades, Lamia, Greece & EU786847 & EU786971 & - & - & NMP 48723 \\
\hline 49Ese GR & Eptesicus serotinus serotinus & Chalkidiki, Greece & AF376837 & AY033950 & - & - & GenBank \\
\hline 50Ese IT & Eptesicus serotinus serotinus & Modena, Italy & EU786848 & EU786972 & EU786900 & KF018981 & Scaravelli, D. \\
\hline 51Ead LA & Eptesicus pachyomus andersoni & Nam Chong River, Novaphan, Laos & EU786849 & EU786973 & EU786901 & KF018982 & EBD25698 \\
\hline 52Ead LA & Eptesicus pachyomus andersoni & Bam Buaphath, Novaphan, Laos & EU786850 & EU786974 & EU786902 & KF018983 & ROM 118316 \\
\hline 53Ese SL & Eptesicus serotinus serotinus & Dobrá Niva, Zvolen, Slovakia & EU786851 & EU786975 & - & - & NMP 9018 \\
\hline 54Ese SP & Eptesicus serotinus serotinus & El Rasillo, La Rioja, Spain & EU786852 & EU786976 & EU786903 & KF018984 & This paper \\
\hline 55Ese SP & Eptesicus serotinus serotinus & Sima de San Pedro, Teruel, Spain & EU786853 & EU786977 & EU786904 & KF018985 & This paper \\
\hline 56Ese SP & Eptesicus serotinus serotinus & Ordesa, Huesca, Spain & EU786854 & EU786978 & - & - & This paper \\
\hline 57Etu SY & Eptesicus serotinus mirza & Slinfeh, Al Lataquieh, Syria & EU786855 & EU786979 & EU786905 & KF018986 & NMP 48058 \\
\hline 58Etu SY & Eptesicus serotinus mirza & Slinfeh, Al Lataquieh, Syria & EU786856 & EU786980 & - & - & NMP 48059 \\
\hline 59Etu SY & Eptesicus serotinus mirza & Safita, Hama, Syria & EU786857 & EU786981 & - & - & NMP 48875 \\
\hline 60Etu SY & Eptesicus serotinus mirza & Hayalien, Hama, Syria & EU786858 & EU786982 & EU786906 & KF018987 & NMP 48924 \\
\hline 61Etu SY & Eptesicus serotinus mirza & Hayalien, Hama, Syria & EU786859 & EU786983 & EU786907 & KF018988 & NMP 48925 \\
\hline 62Ese TU & Eptesicus serotinus serotinus & Tuz G6|єি, Turkey & EU786860 & EU786984 & - & - & NMP 90012 \\
\hline 63Etu TU & Eptesicus serotinus mirza & Van Castle, Anakõz Gate, Turkey & EU786861 & EU786985 & - & - & Karataş, A. \\
\hline 64Ese UK & Eptesicus serotinus serotinus & Devon, United Kingdom & EU786862 & EU786986 & EU786908 & KF018989 & Rossiter, S. \\
\hline 65Ese UK & Eptesicus serotinus serotinus & Somerset, United Kingdom & EU786863 & EU786987 & EU786909 & KF018990 & Rossiter, S. \\
\hline 66Eni GE & Eptesicus nilssonii & Germany & AF376836 & AY033987 & DQ120811 & KF018991 & GenBank* \\
\hline 67Edi VE & Eptesicus diminutus & Guárico, Venezuela & EU786864 & EU786988 & EU786910 & KF018992 & TK15033 \\
\hline 68Efr VE & Eptesicus furinalis & Guárico, Venezuela & EU786865 & EU786989 & EU786911 & KF018993 & TK15160 \\
\hline 69Efs US & Eptesicus fuscus & Texas, USA & EU786866 & EU786990 & EU786912 & KF018994 & TK5893 \\
\hline 70Efs US & Eptesicus fuscus & Massachussets, USA & EU786867 & EU786991 & EU786913 & KF018995 & TK13274 \\
\hline 71Nbr GA & Neoromicia bruneus & Estuaire province, Gabon & EU786868 & EU786992 & EU786914 & KF018996 & TK21501 \\
\hline 72Nso KE & Neoromicia somalicus & Coastal province, Kenya & EU786869 & EU786993 & EU786915 & KF018997 & TK33190 \\
\hline
\end{tabular}


Appendix 1. Continued

\begin{tabular}{|c|c|c|c|c|c|c|c|}
\hline \multirow[b]{2}{*}{ Specimen } & \multirow[b]{2}{*}{ Proposed taxonomy } & \multirow[b]{2}{*}{ Locality } & \multicolumn{4}{|c|}{ GenBank accession no. } & \multirow[b]{2}{*}{ Voucher/source } \\
\hline & & & Cyt b & ND1 & RAG2 & BGN & \\
\hline $73 \mathrm{Vmu} \mathrm{SW}$ & Vespertilio murinus & Valais, Switzerland & AF376834 & AY033964 & EU786916 & KF018998 & GenBank* \\
\hline 74Hca LA & Hypsugo cadornae & Laos & DQ318883 & DQ120797 & DQ120828 & KF018999 & GenBank* \\
\hline $75 \mathrm{Hsa} \mathrm{SP}$ & Hypsugo savii & Spain & DQ120861 & DQ120798 & DQ120825 & KF019000 & GenBank* \\
\hline 77Pku SP & Pipistrellus kuhlii & Spain & DQ120846 & DQ120796 & DQ120829 & KF019001 & GenBank* \\
\hline 79Ppi SP & Pipistrellus pipistrellus & Spain & DQ120854 & DQ120794 & DQ120831 & KF019002 & GenBank* \\
\hline 81Pau SW & Plecotus auritus & Switzerland & AF513758 & - & DQ120821 & KF019003 & GenBank* \\
\hline 82Рau GE & Plecotus auritus & Germany & - & AF401374 & - & - & GenBank \\
\hline 83Pma SP & Plecotus macrobullaris & Spain & AY306213 & AY328904 & DQ120822 & KF019004 & GenBank* \\
\hline 84Mmy GE & Myotis myotis & Germany & AF376860 & AY033986 & - & - & GenBank \\
\hline 85Mmy SP & Myotis myotis & Spain & - & - & DQ120812 & KF019005 & GenBank* \\
\hline 86Msh IR & Myotis schaubi & Choplu, West Azerbaijan, Iran & AF376868 & AY033955 & DQ120818 & - & NMP48130 \\
\hline 90Etu IR & Eptesicus serotinus (=turcomanus) & Sharaf Caravanserai, Khorasan Razni, Iran & EU786870 & EU786994 & EU786918 & - & NMP90779 \\
\hline 91Etu $\mathbb{I R}$ & Eptesicus serotinus (=turcomanus) & Sharaf Caravanserai, Khorasan Razni, Iran & EU786871 & EU786995 & EU786919 & KF019006 & NMP90780 \\
\hline 92Etu IR & Eptesicus serotinus (=turcomanus) & Amir Abad, Khorasan Razni, Iran & EU786872 & EU786996 & EU786920 & - & NMP90800 \\
\hline 93Etu $\mathbb{I R}$ & Eptesicus serotinus (=turcomanus) & Amir Abad, Khorasan Razni, Iran & EU786873 & EU786997 & EU786921 & KF019007 & NMP90801 \\
\hline 94Etu IR & Eptesicus serotinus (=turcomanus) & Korud Abad, SE Ali Abad, Golestan, Iran & EU786874 & EU786998 & EU786922 & KF019008 & NMP90865 \\
\hline 95Etu IR & Eptesicus serotinus (=turcomanus) & Korud Abad, SE Ali Abad, Golestan, Iran & EU786875 & EU786999 & EU786923 & KF019009 & NMP90866 \\
\hline 96Eog IR & Eptesicus ognevi & Shurlaq, Khorasan Razni, Iran & - & - & FJ8419779 & KF019010 & NMP90789 \\
\hline 97Eog IR & Eptesicus ognevi & Amir Abad, Khorasan Razni, Iran & EU786876 & EU787000 & EU786924 & KF019011 & NMP90809 \\
\hline 98Eog IR & Eptesicus ognevi & Amir Abad, Khorasan Razni, Iran & EU786877 & EU787001 & EU786925 & KF019012 & NMP90810 \\
\hline 99EboOM & Eptesicus bottae omanensis & Misfat Al-Khawater, Oman & KF019039 & KF019069 & KF018930 & KF019013 & NMP 93783 \\
\hline 100EboOM & Eptesicus bottae omanensis & $5 \mathrm{~km} \mathrm{~W}$ of Rawdah, Oman & KF019040 & KF019070 & KF018931 & KF019014 & NMP 93793 \\
\hline 101EboOM & Eptesicus bottae omanensis & Al-Khudayrah, Oman & KF019041 & KF019071 & KF018932 & KF019015 & NMP 93818 \\
\hline 102RnaOM & Rhyneptesicus nasutus matschiei & Muntasar, Oman & KF019042 & KF019072 & KF018933 & KF019016 & NMP 93719 \\
\hline 103RnaOM & Rhyneptesicus nasutus matschiei & $2 \mathrm{~km} \mathrm{~S}$ of Al-Rumayliyah, Oman & KF019043 & KF019073 & KF018934 & KF019017 & NMP 93720 \\
\hline 104RnaOM & Rhyneptesicus nasutus matschiei & Al-Ajal, Oman & KF019044 & KF019074 & KF018935 & KF019018 & NMP 93828 \\
\hline 105EanIR & Eptesicus anatolicus & Tadavan, Iran & KF019045 & KF019075 & KF018936 & KF019019 & Aihartza, J. et al. \\
\hline 106EselR & Eptesicus serotinus serotinus & Dashkasan, Iran & KF019046 & KF019076 & KF018937 & KF019020 & Aihartza, J. et al. \\
\hline 107EseGEO & Eptesicus serotinus serotinus & Abano, Tusheti, Georgia & KF019047 & KF019077 & KF018938 & KF019021 & Aihartza, J. et al. \\
\hline 108EseGEO & Eptesicus serotinus serotinus & Dartlo, Tusheti, Georgia & KF019048 & KF019078 & KF018939 & KF019022 & Aihartza, J. et al. \\
\hline 109ESeGEO & Eptesicus serotinus serotinus & Kveda Chkepi, Tmereti, Georgia & KF019049 & KF019079 & KF018940 & KF019023 & Aihartza, J. et al. \\
\hline 110EpalR & Eptesicus pachyomus pachyomus & Dehbarez, Hormozgan, Iran & KF019050 & KF019080 & KF018941 & KF019024 & NMP 48436 \\
\hline 111NguYE & Neoromicia guineensis & Jebel Bura, Riqab, Al Hudaydah, Yemen & KF019051 & KF019081 & KF018942 & KF019025 & PB3124 \\
\hline 112NguYE & Neoromicia guineensis & Jebel Bura, Riqab, Al Hudaydah, Yemen & KF019052 & KF019082 & KF018943 & - & PB3125 \\
\hline $113 \mathrm{Nsc} Y \mathrm{E}$ & Nycticeinops schlieffeni & Kadamat al 'Abali, Lahj, Yemen & KF019053 & KF019083 & KF018944 & KF019026 & PB3602 \\
\hline 114NguYE & Neoromicia guineensis & Ash Shukayrah, Taiz, Yemen & KF019054 & KF019084 & KF018945 & KF019027 & PB3663 \\
\hline 115NguYE & Neoromicia guineensis & Ash Shukayrah, Taiz, Yemen & KF019055 & KF019085 & KF018946 & - & PB3664 \\
\hline 116RnaYE & Rhyneptesicus nasutus batinensis & Al Mawkir, Al Hudaydah, Yemen & KF019056 & KF019086 & KF018947 & KF019028 & PB3708 \\
\hline 117RnaYE & Rhyneptesicus nasutus batinensis & Al Mawkir, Al Hudaydah, Yemen & KF019057 & KF019087 & KF018948 & KF019029 & PB3714 \\
\hline 118NscYE & Nycticeinops schlieffeni & Al Mawkir, Al Hudaydah, Yemen & KF019058 & KF019088 & KF018949 & KF019030 & PB3716 \\
\hline 119NscYE & Nycticeinops schlieffeni & Ba Tays, Abyan, Yemen & KF019059 & KF019089 & KF018950 & KF019031 & PB3801 \\
\hline 120EboJO & Eptesicus bottae innesi & Khirbet Feynan, Karak, Jordan & KF019060 & KF019090 & KF018951 & KF019032 & NMP 92426 \\
\hline 121EboJO & Eptesicus bottae innesi & Al Ghal, Aqaba, Jordan & KF019061 & KF019091 & KF018952 & KF019033 & NMP 92477 \\
\hline 122EboJO & Eptesicus bottae innesi & Al Ghal, Aqaba, Jordan & KF019062 & KF019092 & KF018953 & KF019034 & NMP 92479 \\
\hline 123EseUKR & Eptesicus serotinus serotinus & Uzundja, Crimea, Ukraine & KF019063 & KF019093 & KF018954 & KF019035 & PB4298 \\
\hline 124EseUKR & Eptesicus serotinus serotinus & General'skoe, Crimea, Ukraine & KF019064 & KF019094 & - & KF019036 & PB4362 \\
\hline 125EboOM & Eptesicus bottae omanensis & Al Aqar, Wakan, Oman & KF019065 & KF019095 & KF018955 & - & NMP 92622 \\
\hline 126EboOM & Eptesicus bottae omanensis & Dhahir Al Fawaris, Oman & KF019066 & KF019096 & KF018956 & KF019037 & NMP 92655 \\
\hline 127EboOM & Eptesicus bottae omanensis & Al Nakhar, Oman & KF019067 & KF019097 & KF018957 & KF019038 & NMP 92664 \\
\hline 128EboOM & Eptesicus bottae omanensis & Mansaft, Oman & KF019068 & KF019098 & - & - & NMP 92781 \\
\hline
\end{tabular}

${ }^{*}$ GenBank - Genbank and this paper. 


\section{Supporting Information}

Additional Supporting Information may be found in the online version of this article:

Fig. S1. Comparison between evolutionary hypotheses obtained under Bayesian posterior probabilities for the two mtDNA fragments and according to GTR substitution models.

Fig. S2. Comparison between evolutionary hypotheses obtained under Bayesian posterior probabilities for the two
nuDNA fragments and according to GTR substitution models.

Table S1. Estimates of net divergence between the main taxonomic units studied and obtained using the Kimura 2parameter model (lower semi-matrix) and number of base differences per site (P-value; upper semi-matrix) conducted in MEGA5 Tamura et al. 2011. 